\title{
DIGNIDADE HUMANA E DIREITO AO RECONHECIMENTO DA IDENTIDADE PESSOAL: UMA ANÁLISE A PARTIR DOS INSTRUMENTOS DE PROTEÇÃO EXTRAJUDICIAIS
}

\author{
HUMAN DIGNITY AND THE RIGHT \\ TO RECOGNIZE PERSONAL IDENTITY: \\ AN ANALYSIS FROM EXTRAJUDICIAL PROTECTION INSTRUMENTS
}

\author{
ALOÍSIO ALENCAR BOLWERK ${ }^{1}$ \\ NEUTON JARDIM DOS SANTOS ${ }^{2}$
}

\section{RESUMO}

O presente artigo pretende estabelecer um elo entre o princípio da dignidade da pessoa humana e o direito ao reconhecimento da identidade pessoal, com abordagem de alguns instrumentos de proteção, especialmente os extrajudiciais, a exemplo dos provimentos do Conselho Nacional de Justiça (CNJ). Como metodologia, utilizam-se o método indutivo para abordagem e a técnica de pesquisa bibliográfica na área doutrinária e de legislação sobre identidade, identidade humana, reconhecimento e direito ao reconhecimento da identidade pessoal, levando em consideração os conceitos, a natureza e os dados sobre esse reconhecimento no Brasil. Estabelece-se, assim, vínculo com o princípio do acesso à justiça e o princípio da dignidade da pessoa humana. A pesquisa bibliográfica decorreu de dados levantados sobre o tema no período de março a junho de 2020 e incidiu, no âmbito do CNJ, prioritariamente, sobre os Provimentos $n^{\circ}$ 28/2013, 63/2017, 73/2018, 82/2019 e a Resolução Conjunta CNJ/CNMP nº 3/2012.0 resultado obtido a partir dessas considerações é uma análise crítica sobre a efetividade desses instrumentos de proteção extrajudiciais, com o objetivo de contribuir para a consecução dos direitos fundamentais do acesso à justiça e da dignidade da pessoa humana.

Palavras-chave: Dignidade humana. Identidade pessoal. Proteção extrajudicial.

1 Doutor em Direito Privado pela PUC Minas. Professor adjunto da Universidade Federal do Tocantins - UFT e Professor Permanente do Programa de Mestrado Profissional em Prestação Jurisdicional e Direitos Humanos da UFT/Esmat. Líder do Grupo de Pesquisa em Direitos Humanos e Prestação Jurisdicional. Advogado. ORCID iD: http://orcid.org/0000-00034229-4337. E-mail: bolwerk@uft.edu.br.

2 Mestrando em Prestação Jurisdicional e Direitos Humanos pela Universidade Federal do Estado do Tocantins em parceria com Escola da Magistratura do Estado do Tocantins (ESMAT). Graduado em Direto pelo Centro Universitário Unirg. Especialista em Direito Civil e Processo Civil pela Unitins. Especialista em Direito Público pelo ITOP. Especialista em Direito e Processo Constitucional pela Universidade Federal do Tocantins. É Defensor Público na Defensoria Pública do Estado do Tocantins e Diretor da Escola Superior da Defensoria Pública do Estado do Tocantins. ORCID iD: https://orcid.org/00000002-0160-8072. E-mail: neutonjardim@hotmail.com. 


\section{ABSTRACT}

This article sought to establish a link between the principle of the dignity of the human person and the right to recognition of personal identity, addressing some protection instruments, especially extrajudicial ones, such as the provisions of the National Council of Justice. An inductive method will be used to approach it, presenting an overview of the technique of bibliographic research, doctrine and legislation on the right to personal identity recognition, with concepts, nature and data on this recognition in Brazil, establishing a link with the principle of access to justice and on the principle of human dignity. Based on these considerations, a critical analysis will be carried out on the effectiveness of these extrajudicial protection instruments, with the objective of contributing to the realization of the fundamental rights of access to justice and the dignity of the human person.

Keywords: Human dignity. Personal identity. Extrajudicial protection.

\section{INTRODUÇÃO}

Desde a pré-história, a datar do momento em que o homem passou a se aglomerar e surgiram as primeiras comunidades, os indivíduos passaram a procurar formas de se identificar, de modo a criar uma identidade pessoal própria, a se individualizar.

Segundo Calissi(2016),

A identidade é um termo de reconhecimento perante o "outro" e termo de autoconhecimento. De um lado, a pessoa existe porque é composta internamente como manifestação de sua mente, de seu pensamento, mas existe, também, socialmente, porque percebida pelo "outro". Assim, a identidade é o conhecimento do sujeito a partir de si mesmo e a partir do outro. (CALISSI, 2016, p. 115)

O direito à identificação pessoal ultrapassa os limites clássicos do Direito Privado e do Direito Público, de modo que devemos protegê-lo de maneira interdisciplinar, em juízo ou fora dele, seja de forma repressiva, ao corrigir danos à identidade, seja de forma fomentadora, ao divulgar e instigar a proteção a esse direito. Nesse segmento, estão os direitos ao nome, à identidade cultural, a conhecer as próprias origens e à liberdade de orientação sexual, entre outros (KONDER, 2018). 0 direito ao nome e à identidade exigem assentos oficiais substanciais e hígidos, podem proteger uma cultura, a exemplo das etnias indígenas, referendam uma origem genética, bem como reclassificam o sexo como condição autopercebida ou autodeclarada, no caso de pessoa transgênero.

Segundo o Instituto Brasileiro de Geografia e Estatística (IBGE, 2019), na região norte, a cobertura do Registro Civil de Pessoas Naturais é de apenas $87,5 \%$ enquanto em todas as demais regiões do país supera $93,1 \%$. Os mais atingidos com subregistro são indígenas, população em situação de rua, trabalhadores rurais e população LGBTT, o que se traduz em um abalo à dignidade da pessoa humana(INSTITUTO BRASILEIRO DE GEOGRAFIA E ESTATísTICA, 2019).

Erros e omissões nos assentos de registros públicos de nascimento, casamento e óbito junto aos cartórios do registro civil de pessoas naturais são comuns, o que inviabiliza ou retarda também o exercício de direitos como à moradia, de ir e vir, patrimonial e outros servi- 
ços públicos. Logo, há necessidade de buscar fomento de atividades que possibilitem tornar eficaz a entrega desses direitos fundamentais que garantem o exercício da cidadania.

Recentemente, o Supremo Tribunal Federal (STF), na Ação Direta de Inconstitucionalidade (ADI) n ${ }^{\circ} 4275$, autorizou a alteração de registro civil de nascimento ou casamento para adaptar a realidade declarada da pessoa transgênero. E o Conselho Nacional de Justiça (CNJ) editou vários provimentos, facultando registros e retificações extrajudiciais pelos cartórios de registro civil de pessoas naturais ${ }^{3}$, a indicar, em ambas as situações, a primazia pelo direito à dignidade dos cidadãos.

Este artigo pretende justificar o reconhecimento do direito à identidade pessoal como um direito fundamental, com base no princípio da dignidade da pessoa humana, norte orientador na Constituição Federal brasileira. A partir dos direitos da personalidade, estabeleceu-seconexão com o direito à identidade pessoal com a finalidade de afirmar que é um direito que deve receber tutela judicial ou extrajudicial, sempre à luz do princípio da dignidade da pessoa humana.

Outro enfoque foi o acesso à justiça plena para concretização desses direitos, o que foi feito explorando princípios constitucionais, leis e atos administrativos do CNJ. Para a análise do tema, adotou-se o método de abordagem indutivo, por necessidade de comprovação de que o direito à identidade pessoal e sua respectiva tutela são direitos fundamentais e de que a conclusão está baseada em princípios constitucionais e em valores éticos. Como técnica de estudo(métodos de procedimentos), utilizou-se a pesquisa bibliográfica, doutrinária e de legislação, já que o tema em estudo tem relação com esses elementos de pesquisa.

0 texto estrutura-se, além desta introdução, em três partes. Na primeira, abordam-se direito à dignidade da pessoal humana, conceitos e normatização internacional e interna e principiologia. Na segunda, abordam-se identidade, identidade humana, reconhecimento e direito à identidade pessoal sob a ótica doutrinária e constitucional, estabelecendo-se conceitos e sua natureza jurídica. Na terceira, são feitas considerações sobre instrumentos de proteção judicial e extrajudicial desses direitos com base na lei e em normas técnicas emitidas pelo $\mathrm{CNJ}$, com enfoque no acesso à justiça e na duração razoável do processo, dando destaque às medidas positivas e negativas para ampliação de tutela ao direito à identidade e citando, em tópico específico, o caso concreto da ADI n 4275 e do Provimento n $73 / 2018$ do CNJ.

Pretende-se com este trabalho contribuir para aprofundar os conhecimentos sociais do direito, na medida em que são discutidos ensinamentos sobre direitos humanos, princípios constitucionais da dignidade da pessoa humana e meios de acesso à justiça a partir da resposta extrajudicial. 


\section{CONSIDERAÇÓES ACERCA DA DIGNIDADE DA PESSOA HUMANA}

A Declaração Universal de Direitos Humanos estabelece, na parte preambular, que "o reconhecimento da dignidade inerente a todos os membros da família humana e de seus direitos iguais e inalienáveis é o fundamento da liberdade, da justiça e da paz no mundo", e, no seu art. $1^{\circ}$, que "todas os seres humanos nascem livres e iguais em dignidade e direitos" (NAÇÕES UNIDAS BRASIL, 1948, p. 2).

Para Piovesan (2019), a Declaração de 1948 introduz a concepção contemporânea de direitos humanos, enfatizada pela universalidade e pela indivisibilidade. Universalidade porque clama pela extensão universal dos direitos humanos sob a crença de que a condição de pessoa é o requisito único para a titularidade de direitos; e indivisibilidade porque a garantia dos direitos civis e políticos é condição para a observância dos direitos sociais, econômicos e culturais e vice-versa.

Os direitos humanos consistem em um conjunto de direitos considerado indispensável para uma vida humana pautada na liberdade, na igualdade e na dignidade. Enfatizam, mais, que a dignidade da pessoa humana é uma categoria jurídica que, por estar na origem de todos os direitos humanos, confere-lhes conteúdo ético e dá unidade axiológica a um sistema jurídico, fornecendo um substrato material para que os direitos possam florescer. Logo, o conceito de dignidade humana é polissêmico e aberto, em permanente processo de desenvolvimento e construção (RAMOS, 2020).

A dignidade da pessoa humana foi colacionada no artigo $1^{\circ}$ da Constituição Federal de 1988 (CF/88) enquanto fundamento da República Federativa do Brasil, sendo princípio singular e irradiador do texto constitucional. Bulos (2018) assevera que a dignidade da pessoa humana é diretriz cogente para desenho do Estado, determinando-Ihe o modo e forma de ser, e que garante unidade constitucional e baliza interpretações para a tomada de decisões.

Sobre o princípio da dignidade da pessoa humana, o autor ainda destaca que:

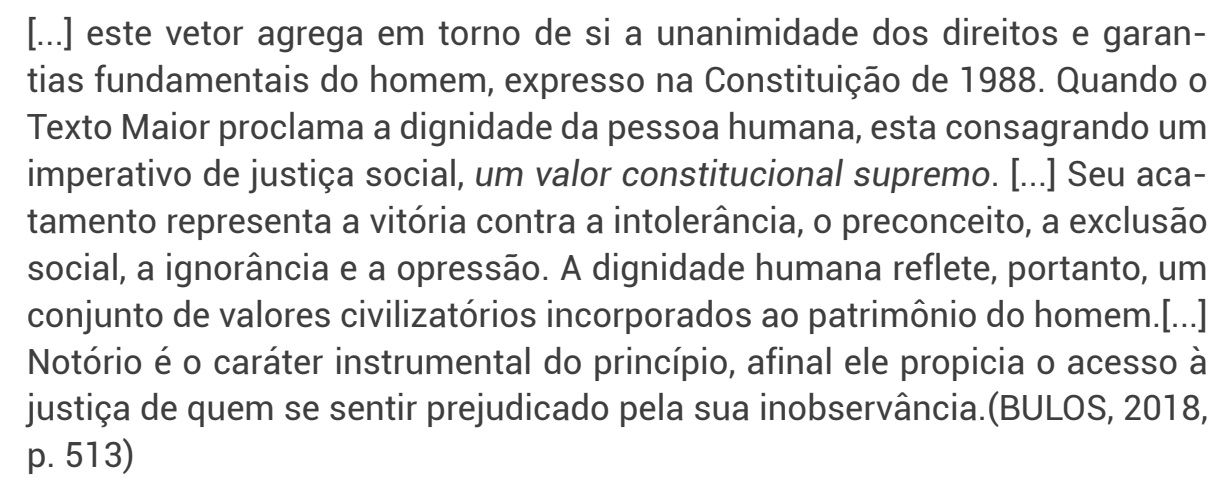

$\mathrm{Na}$ filosofia, temos a corrente kantiana, que defende ser o homem o fim em si mesmo e que a dignidade humana se funda na capacidade humana de propor fins e, não apenas, autonomia. É dizer, todos os seres humanos têm dignidade, independentemente de sua condição, de modo que, devemos respeitar a humanidade, sempre, como fim em si mesmo e nunca, meramente, como meio (KANT, 2009). A dignidade humana existe como meta finalística em favor da humanidade, como regra moral e um "dever-ser" necessário e universal. As pessoas têm, sempre, dignidade. 
Para Reale, "o homem não é uma simples entidade psicofísica ou biológica, redutível a um conjunto de fatos explicados pela Psicologia, pela Física, pela Anatomia, pela Biologia". 0 autor continua o pensamento, afirmando que nele existe algo que representa a possibilidade de inovação e superação. 0 homem representa algo que é um acréscimo à natureza como instaurador de novos objetos do conhecimento, como no ato constitutivo de novas formas de vida (REALE, 2002, p. 211).

É claro, o elo que liga a dignidade da pessoa humana ao direito de identidade pessoal, como forma de estabelecer os anseios de pertencimento, seja pertencimento individual do ser ao seu mundo particular, seja pertencimento coletivo, a um contexto cultural(CALISSI, 2016).

Desse modo, a dignidade da pessoa humana reforça que o direito à identidade pessoal deve ser aperfeiçoado como meta humanitária, com vistas à plena realização do homem como fim em sim mesmo.

\section{O DIREITO À IDENTIDADE PESSOAL}

As relações sociais são ordenadas por normas e princípios, que objetivam, não somente, protegê-los como assegurar-lhes direitos e impor-lhes deveres.

Urge estabelecer os conceitos de identidade, identidade humana, identificação e reconhecimento. Em medicina legal, a antropologia forense fixa que a identidade é "o conjunto de caracteres próprios e exclusivos das pessoas, dos animais, das coisas, dos objetos. É a soma de sinais, marcas e caracteres positivos ou negativos que, no conjunto, individualizam o ser humano ou uma coisa, distinguindo-os dos demais"(CROCE JR., 2011, p. 63).

Cumpre distinguir identidade humana e identificação. Para Croce Júnior(2011), identidade humana é "o conjunto de característicos pessoais e peculiares que diferencia o indivíduo dos outros e the confere uma situação temporoespacial específica e status social único enquanto identificação é a determinação da identidade, ou seja, da individualidade. É a demarcação da individualidade".

França(2015) distingue reconhecimento e identificação, ao dizer que o primeiro significa apenas $\mathrm{o}$ ato de certificar-se, conhecer de novo, admitir como certo ou afirmar conhecer; e identificação consiste em um conjunto de meios científicos ou técnicas específicas empregados para que se obtenha a identidade.

Num viés psicológico, Jacques (1998apud HOGEMANN; MOURA, 2018) sustenta que a identidade pessoal é a maneira pela qual as pessoas enxergam a si mesmas e está intimamente relacionada à própria imagem, ao passo que, sob um olhar sociológico, é um construir-se por meio do processo de socialização, que se dá até a morte.

A Declaração sobre o Genoma Humano e os Direitos Humanos (DUGHDH) garante, em seu art. $1^{\circ}$, que "o genoma humano tem subjacente a unidade fundamental de todos os membros da família humana, bem como reconhecimento de sua inerente dignidade e diversidade. Em sentido simbólico, constitui o patrimônio da Humanidade". A identidade pessoal, sob esse viés, passa pela determinação da origem genética, conferindo a característica a todos 
aqueles que pertencem à espécie humana, e, no particular, expressa os caracteres do patrimônio genético individualizador recebido dos pais, na concepção, fundamental para a plena integridade psíquica (UNESCO, 1997).

Evidenciado que a identidade humana é um conjunto de caracteres pessoais encontrado pelo processo de identificação, que é o meio para demarcá-la, é de se consignar que a identidade da pessoa humana deve ser encarada como necessidade psicológica, social, individual, cultural e genética.

O contexto da dignidade da pessoa humana expressa que, o homem é o centro, de modo que, o indivíduo exista, mas, de forma digna, com sua identidade, suas diferenças e sua cultura, e que o Estado possibilite meios para essa realização. Emerge da dignidade da pessoa humana, o direito à identidade pessoal, também reconhecida pela Declaração Universal dos Direitos Humanos em seu artigo $6^{\circ}$, que dispõe que, "todo ser humano tem o direito de ser, em todos os lugares, reconhecido como pessoa perante a lei" (NAÇÕES UNIDAS BRASIL, 1948, p. 6).

Muito embora o reconhecimento ao direito à identidade pessoal não se restrinja ao reconhecimento do direito a ter nome, parte-se aqui desse elemento para levar em consideração as demais necessidades, pois deve-se garantir que se agreguem ao nome, direito nato e personalíssimo, as necessidades psicológicas, sociais, individuais, culturais e genéticas.

Um dos elementos da identidade pessoal é o nome. A partir da coerente e oportuna classificação doutrinaria de Orlando Gomes(2019) para a discussão em tela, há, em resumo, três teorias principais para explicar a natureza jurídica do direito ao nome civil: teoria da propriedade, teoria do Estado e teoria do direito da personalidade.

A primeira entende que o nome é natureza patrimonial de que goza o sujeito de forma absoluta. A segunda defende que o nome é um fato protegido pela ordem jurídica. E a terceira, sobre a qual será dedicada maior explanação neste artigo, estabelece que o nome pertence aos direitos da personalidade, teoria adotada pelo atual Código Civil Brasileiro.

O reconhecimento da identidade pessoal passa pela existência pessoal e social, de modo que cada pessoa tem direito ao nome, nele compreendidos o prenome e o sobrenome, conforme propõe o artigo 10 do Código Civil. Trata-se de direitos da personalidade, com previsão no Livro I, Título I, Capítulo II do Código Civil Brasileiro.

Para Almeida (2017), devemos

Recompor a sistemática atinente à tutela do nome à luz do princípio da dignidade da pessoa humana significa concretizar uma qualificação civil condizente com uma real individualização perante si e seus semelhantes. Em outras palavras, o nome deve servir, enquanto signo distintivo exterior e visível de individualização, como uma expressão concreta do princípio da dignidade da pessoa humana. (ALMEIDA, 2017, p. 1.153)

Konder (2018) vem conceituando que:

0 direito à identidade pessoal deve dar guarida à construção coletiva e dialógica das identidades, protegendo o próprio processo pelo qual as identidades se constroem intersubjetivamente [...] é imprescindível recorrer aos desenvolvimentos científicos da psicologia, da antropologia e da sociologia, e ainda, dentro do direito, aos estudos da filosofia do direito, do direito constitucional e, claro, do direito civil. (KONDER, 2018, p. 4-5) 
Ser titular de direito da personalidade é garantia de que o indivíduo possa ter um nome, um caractere específico e um distintivo. Essa individualização exige, na sua formatação, elementos que reflitam sua satisfação e respeitabilidade, sem que haja exposição ao ridículo ou constrangimento pessoal e, ainda, possa expressar suas origens, sua cultura e sua maneira de se perceber no cosmo. A necessidade de estabelecer reconhecimento pessoal e social fez que a identidade pessoal ganhasse corpo, com matrizes normativas que assegurem sua proteção.

O reconhecimento como pessoa, individual ou socialmente, concretiza-se como direito da personalidade, que nasce com o ser humano e reflete na necessidade de defesa substancial perante a sociedade, com garantias de instrumentos eficazes para essa proteção.

\subsection{A PROTEÇÃO DO DIREITO À IDENTIDADE: UMA ANÁLISE}

\section{A PARTIR DOS INSTRUMENTOS EXTRAJUDICIAIS}

Como roteiro lógico e equilibrado, onde há estabelecimento de direitos, deve haver, seguramente, meios de proteção. Não adianta estabelecer direitos sem regras de proteção.

A defesa dos direitos à identidade pessoal, nos mais variados aspectos- nome civil, adaptação do nome ao sexo biológico, inclusão ao nome dos aspectos culturais de um povo, nome dos pais biológicos, direito a ter o registro do nome oficialmente, bem como suas retificações ou alterações - somente é possível se o cidadão tiver o pleno acesso à justiça.

No plano internacional existem pactos e convenções, que corroboram o escopo do princípio do acesso à justiça e a inafastabilidade da jurisdição, a exemplo da Declaração Universal dos Direitos Humanos, nos termos do artigo 10, da Convenção Europeia para a Salvaguarda dos Direitos do Homem e das Liberdades Fundamentais, de acordo artigo $6^{\circ}, 1$, do Pacto Internacional de Direitos Civis e Políticos, nos termos do artigo 14, 1 e da Convenção Americana sobre Direitos Humanos de São José da Costa Rica, nos termos do artigo $8^{\circ}, 1$. A Constituição Federal brasileira expressa que a lei não excluirá da apreciação do Poder Judiciário, lesão ou ameaça de lesão, nos termos do artigo $5^{\circ}, \mathrm{XXXV}$.

No Brasil, a Lei de Registros Públicos, Lei nº 6.015/73, orienta o serviço estatal comprometido com a autenticidade, a segurança e a eficácia dos atos jurídicos; Um dos papéis desse serviço é o registro civil de pessoas naturais, a exemplo de nascimento, emancipações, casamentos e óbitos. Essa lei veio para corporificar o direito existencial, corrigir falhas e, sobretudo, garantir meios para obtenção da cidadania.

Para que possam cumprir, correta e eficientemente o dever de velar pela validade e eficácia, publicidade e segurança dos negócios. Os registradores devem ter amplo conhecimento do Direito Privado e de aspectos do Direito Público, por isso são considerados profissionais do direito. Tanto isso é verdade que a lei lhes confere o dever funcional de se manterem atualizados no tocante às matérias de lei e aos correspondentes regulamentos administrativos que digam respeito à sua atividade, pondera Loureiro(2018).

A proteção dos direitos da personalidade dá-se em vários campos do ordenamento jurídico e poderá ser realizada de forma preventiva ou repressiva, haja vista a previsão constitucional do princípio da inafastabilidade da jurisdição. A tutela preventiva abrange, logicamente, o caráter promocional dessa defesa. 
A tutela à identificação pessoal, amparada por lei ou normas técnicas, pode ser processada pela via judicial ou extrajudicial. Atende ao caráter preventivo, repressivo ou promocional do direito à identidade pessoal, de modo que seja um instrumento capaz de ser utilizado por todos, com plena eficácia em resultados desejados pelos interessados. Preservam-se, assim, a dignidade da pessoa humana, o acesso à justiça e a celeridade de tramitação processual.

A tutela judicial do direito à identidade pessoal é sempre possível para que se possa obter, entre outros, modificação, alteração ou retificação de nome, alteração ou supressão de prenome, correção de dados primários ou acessórios do registro civil de nascimento, óbito ou casamento.Visa a atender ao princípio da realidade fática entre o assento no registro e o indivíduo que o ostenta e prescinde de exaurimento das vias extrajudiciais. Logo, judicialmente, pode-se pleitear a defesa dos direitos à identidade que seja autorizada pela via administrativa(extrajudicial).

Loureiro (2018) entende que, em regra, o nome goza de imutabilidade, mas exemplifica a permissão da modificação para retificações ou alteração do registro civil de pessoas naturais nos casos de alteração do gênero, conforme propõe artigo 58 da Lei n 6015/73, com interpretação dada pela ADI 4275(STF).

Como medida de tutela correta e eficaz, a Emenda Constitucional n ${ }^{\circ} 45 / 2004$ estabeleceu a razoável duração do processo e os meios que garantam a celeridade de sua tramitação, como propõe artigo $5^{\circ}, \mathrm{LXXVIII,} \mathrm{da} \mathrm{CF/88,} \mathrm{de} \mathrm{modo} \mathrm{a} \mathrm{assegurar} \mathrm{a} \mathrm{dignidade} \mathrm{da} \mathrm{pessoa}$ humana na prestação jurisdicional, bem como criou o $\mathrm{CNJ}$, órgão máximo administrativo do Poder Judiciário nacional. 0 Código de Processo Civil (CPC), em seu artigo $4^{\circ}$, como ênfase ao acesso à justiça, fez coro à Emenda Constitucional n 55/2004, trazendo idêntica disposição.

Acerca da tutela extrajudicial, com a criação do CNJ, possibilitou-se a edição de vários atos normativos como provimentos e resoluções, autorizando a proteção do direito à identidade por meio de pedido extrajudicial diretamente pelo interessado aos cartórios de registro civil de pessoas naturais.

Nesse ponto, constata-se a efetiva e necessária atuação do CNJ para obtenção, sem necessidade de intervenção de um juiz de direito nem de um membro do Ministério Público, de alteração, modificação ou retificação registral. 0 exercício do direito de petição para defesa de direitos pessoais pode ser direto, sem advogado, sem defensor público ou sem procurador.

A medida desjudicializante é a expressão da facilitação do acesso à justiça e teve também fundamentos técnicos, jurisprudenciais e gerencial, do Poder Judiciário, mas sempre mirando a dignidade do cidadão e sua plena harmonização com sua ordem existencial ontológica. A tutela extrajudicial pode ser albergada, entre outros, a partir dos provimentos do CNJ.

Assim, tem-se o provimento, que trata do registro tardio de nascimento por oficial do registro civil de pessoas naturais (Prov. $n^{\circ} 28 / 2013$ ); o que dispõe sobre o registro de nascimento e emissão da respectiva certidão dos filhos havidos por reprodução assistida por oficial de registro civil de pessoas naturais (Prov. n 63/2017); o provimento sobre a averbação da alteração do prenome e do gênero nos assentos de nascimento e casamento de pessoa 
transgênero no registro civil de pessoas naturais (Prov. $n^{\circ} 73 / 2018$ ); o Provimento $n^{\circ} 82$, que dispõe sobre procedimento e averbação no registro de nascimento e no de casamento dos filhos e alteração do nome do genitor e dá outras providências; e, ainda, a Resolução Conjunta CNJ/CNMP n 3 , de 19 de abril de 2012, que possibilita o registro civil dos indígenas.

No Provimento $n^{\circ} 28$, por exemplo, procura-se combater, sobremaneira, a ocorrência do subregistro civil de nascimento no Brasil que, na Região Norte, representa $12,5 \%$ dos nascimentos (INSTITUTO BRASILEIRO DE GEOGRAFIA E ESTATÍSTICA, 2019), dando-se possibilidade direta aos interessados de ter corporificada a sua existência e o seu pertencimento, perante a sociedade, deixando-se de viver na invisibilidade. É o provimento que regula o registro de nascimento extemporâneo, ou seja, fora do prazo.

O Provimento $n^{\circ} 73$, consequência do julgamento pelo STF da ADIn 4275 , - que autorizou a alteração de registro civil de nascimento ou casamento para adaptar à realidade declarada da pessoa transgênero-, permite que o interessado, sem processo judicial e parecer do Ministério Público, possa averbar diretamente no cartório, o seu direito fundamental à identidade de gênero, estabelecendo a realidade do sexo psicológico. Privilegiou-se a realidade autopercebida como forma de garantir o princípio fundamental da dignidade da pessoa humana e o efetivo acesso à justiça.

$\mathrm{O}$ registro civil de indígena não integrado é facultativo. No entanto, a identidade cultural dos povos indígenas é fomentada também pela Resolução Conjunta CNJ/CNMP n 3, de 19 de abril de 2012, de modo a possibilitar registros civis dos indígenas também pela via extrajudicial.

Recentemente, foi editado o Provimento $n^{\circ} 82 / 2019$, que facilitou, sobremaneira, a vida das pessoas que tiveram alterações no nome dos genitores ao incluírem o patronímico do cônjuge em razão de casamento, assim como de separação ou de divórcio. Esse provimento permitiu que as pessoas pudessem voltar a usar nome de solteira-(o), possibilitando averbação desse acréscimo no assento de nascimento dos filhos para refletir o atual nome dos pais, bem como averbar a alteração do nome dos pais, quando voltar nome de solteiro (decote patronímico do cônjuge pelo casamento). Isso será possível, doravante, diretamente no cartório de registro civil, nos termos da referida resolução.

Exemplo de aplicação do Provimento n 82/2019 é que, havendo divórcio ou separação judicial e o cônjuge voltar a usar nome de solteiro, poderá postular modificação no assento de nascimentos dos filhos, alterando nome da mãe ou do pai, modificado pelo divórcio ou pela separação judicial, sem ordem judicial, para adaptar à realidade atual do status dos pais. Igual postulação foi permitida, em caso de morte de um dos cônjuges, em que poderá pedir o cônjuge sobrevivente que volte a usar o nome de solteiro(a), diretamente em cartório, onde foi feito assento do casamento, sem ordem judicial nem parecer do Ministério Público.

Elencam-se tais provimentos como demonstração de que, os princípios da dignidade humana e da cidadania são guias das políticas e de acesso à justiça. Contudo, é notório que, a justiça, ainda que mais acessível, como se vê, pode ter entraves diante do sistema de custeio das atividades dos cartórios extrajudiciais no país, já que, os oficiais e tabeliães não são remunerados pelo Poder Judiciário, sendo tal incumbência de quem solicitar o serviço delegado, de acordo com lei de emolumentos da cada unidade da Federação. Perquire-se, portanto, a afetividade normativa dessas políticas de proteção diante da necessidade de 
pagamento de emolumentos pelos usuários hipossuficientes, como propõe artigo 28 da Lei $n^{\circ} 8.935 / 94$.

Nessa circunstância, a gratuidade dos atos às pessoas declaradamente pobres perante os cartórios revela-se também um instrumento de eficiência para garantia da tutela plena do direito à identidade. A Cártula Federal, conforme artigo $5^{\circ}, \mathrm{LXXVII}$, estabeleceu que são gratuitos, na forma da lei, os atos necessários ao exercício da cidadania.

Para regulamentar a norma constitucional de eficácia contida e garantir desenvolvimento social, o Brasil editou a Lei n $9.534 / 97$, estabelecendo o seu art. $1^{\circ}$ que"são gratuitos os atos necessários ao exercício da cidadania, assim considerados: [...] o registro civil de nascimento e o de óbito, bem como a primeira certidão respectiva". Tais normas, seguramente, facilitam o acesso ao serviço de registro civil de pessoas naturais e podem diminuir o subregistro civil de nascimentos.

Muitas são as causas, por exemplo, que levam ao subregistro civil de nascimento. Guimarães (2015) cita, entre outras, desinformação, descaso, desconhecimento. Córcova (1998) faz referência à opacidade do direito e propõe informar que, entre o direito e seu destinatário (homem comum), há uma barreira opaca, que não é transparente, tornando-se o homem comum sem possibilidades de absorção da mensagem e dos sentidos do direito, bem como de utilização dos instrumentos de que poderia se beneficiar.

A ausência de acesso à informação de políticas de ensino e divulgação dos direitos da cidadania contribui para travar o acesso pleno aos instrumentos quegarantemplena satisfação dos direitos humanos, especialmente da proteção da identidade pessoal.

A ineficácia ou insuficiência das medidas desjudicializantes pode comprometer o acesso à justiça, de modo que devemos discutir meios de sua maior incidência, seja difundindo-as, seja com medidas de orientação.

Para Cappelletti (1988), a acepção de acesso à justiça tem finalidades básicas de como o sistema jurídico deve ser igualmente acessível a todos e de que, os resultados produzidos precisam ser individual e socialmente justos. Além disso, o autor defende que, acesso à justiça pode, portanto, ser considerado como requisito fundamental de um sistema jurídico moderno e igualitário que pretende garantir, e, não apenas, proclamar direitos de todos.

Diante disso, as retificações ou alterações extrajudiciais do registro civil das pessoas naturais surge como paradigma para complementação do modelo judicial nas Varas de Registros Públicos, superando as limitações destas, pois se apresentam como instrumento de resolução extrajudicial de conflito baseado na dignidade da pessoa humana e na célere duração do processo, na inclusão social, buscando-se a harmonização do acesso à justiça.

\subsection{O CASO DA ADI No 4275 E DO PROVIMENTO No 73/2018 DO CNJ: UMA ANÁLISE CONCRETA DE DOMÍNIO PÚBLICO}

Com objetivo de demonstrar a força da proteção dos direitos da identidade pessoal, citamos o julgamento da ADI $n^{\circ} 4275$, de $1^{\circ}$ março de 2018, pela qual o STF entendeu ser possível a alteração de nome e gênero no assento de registro civil diretamente nos cartórios de registro civil de pessoas naturais, mesmo sem a realização de procedimento cirúrgico de 
redesignação de sexo, sem apresentação de laudos médicos ou psicológicos e sem necessidade de processo judicial e parecer do Ministério Público.

A ação foi ajuizada pela Procuradoria-Geral da República com objetivo de se estabelecer uma interpretação, conforme a Constituição Federal, do art. 58 da Lei n 6.015/73, que trata da possibilidade de alteração do nome e do prenome.

O Poder Judiciário brasileiro, com essa interpretação, deu um passo histórico para a valorização da identidade de gênero e autodeclarada por pessoa transgênero, de modo a dar-Ihes dignidade na sua identificação pessoal e psicológica, podendo ostentar, em seus documentos, o que realmente sentem no seu psíquico e na sua realidade social, observável por todos.

As razões do julgamento foram orientadas pelo princípio basilar da dignidade da pessoa humana, direito a uma ordem jurídica inclusiva, à autoidentificação, não discriminação por orientação de sexo ou gênero, liberdade e igualdade.

Como ponderaram Menezes e Lins(2020)

Parte-se da premissa de que a pessoa humana é livre no processo de desen-
volvimento de sua personalidade e, consequentemente, na sua afirmação
identitária. Reitera-se que o gênero não é uma condição biológica inata, cris-
talizada nos determinantes do sexo cariotípico. Resulta de uma construção
subjetiva ao longo da vida, que deve ser acatada como uma manifestação da
personalidade, a ser reconhecida pelo Estado e respeitada pela sociedade,
independentemente de 'qualquer' readequação corporal do sexo genético.
Por isso, não é demais destacar que a identidade de gênero em desacordo
com o sexo biológico não constitui efeito patológico a ser corrigido, nem um
desvio moral a ser repreendido. (MENEZES; LINS, 2020, p. 18)

Logo após o julgamento pelo STF, ocorreu um vácuo normativo nacional sobre como esses pedidos administrativos seriam feitos junto aos cartórios. Isso se deu por três meses da data do julgamento, quando então o CNJ editou o Provimento $n^{\circ} 73$, de 28 de junho de 2018 , com base no poder de orientação e estabelecimento de normas técnicas, com o passo a passo para, enfim, uniformizar os pedidos dos interessados em todo o país.

O Provimento $n^{\circ} 73$ exige, para efetuar averbação de prenome e gênero, idade mínima de 18 anos, comparecimento ao cartório de registro civil de pessoas naturais, bem com requisitos obrigatórios e facultativos. Dentre os documentos obrigatórios, estão documentos pessoais do interessado, comprovante de endereço, certidão do distribuidor cível, criminal e execução criminal do local da residência dos últimos cinco anos (estadual e federal), certidão dos tabelionatos de protestos, da Justiça Eleitoral e do Trabalho, do local da residência dos últimos cinco anos e certidão da Justiça Militar, se for o caso. Como documentos facultativos, laudos médicos e pareceres psicológicos que atestem a transexualidade/travestilidade e a realização de cirurgia de redesignação de sexo.

Muito comemorada a chegada da normatização, mas sem comprovação de efetividade abrangente que contemplasse uma considerável gama de transgênero, especialmente pela dificuldade na obtenção da gratuidade nos cartórios de registro civil de pessoas naturais, já que a maioria dos potenciais interessados sofre com a exclusão social e familiar.

Embora tenha a sua importância para efetivação dos direitos da comunidade transgênero, o Provimento $n^{\circ} 73$ poderia ser mais enfático nos fatores da estruturação das fontes 
de custeio desses serviços, prevendo expressa e diretamente, no documento, a uniformização e a simplificação de procedimentos, seja nos cartórios, seja na Central de Informações do Registro Civil(Provimento n 38/2014 da Corregedoria Nacional de Justiça), para, por exemplo, dispensar os interessados de comparecimento direto nos cartórios para formalizar o pleito, o que poderia ser feito por procuradores (pessoas físicas, advogados, defensores públicos).

\section{CONSIDERAÇÓES FINAIS}

Diante das abordagens apresentadas neste artigo, é imperioso reconhecer que, os direitos humanos são necessários para construção de pacto social, estabelecendo um conjunto de valores diretivos. Constituem o elemento ético e informativo de todo um sistema jurídico e evoluem a cada momento histórico, diante da elevada dinamicidade de seu conteúdo e indispensável para uma vida humana pautada na liberdade, na igualdade e na dignidade

O sistema jurídico tem foco no ser humano e o Estado tem o dever de promover a dignidade de seu povo. Foca-se no cidadão. O homem é o centro, seguramente, e convive com as estruturas de Estado.

Os direitos humanos, na Constituição Federal brasileira, inserem-se na cláusula de não taxatividade para que os fundamentos da República Federativa do Brasil sejam efetivos, e aptos a deferir com maior concretude a dignidade da pessoa humana, pois esta é medida guia para os intérpretes e poderes, tanto nas relações públicas quanto privadas.

Constata-se que ao ser humano, como fim em si mesmo, deve-se deferir uma identidade, um signo representativo das construções sociais como uma necessidade individual, psicológica, social, cultural e genética. Para isso, confere-se um processo de identificação que pode ser atestado pelo reconhecimento de uma identidade pessoal.

Um dos elementos importantes da identificação pessoal é o nome, um direito da personalidade, segundo previsão do Código Civil Brasileiro. Devemos atribuir uma recomposição à função do nome, como norte do direito da identidade pessoal, com o fim de conclamar necessidades de quem o ostenta, especialmente aos fins psicológicos, como nos casos da pessoa transgênero, seja aos fins culturais, no caso de agregação ao nome da etnia indígena a que pertence, seja nos casos de reconhecimento e registro tardio para reconhecimento da identidade genética do pai biológico.

Fica, com isso, estabelecido que, o direito de identificação pessoal, que no Brasil tem a natureza jurídica de direito da personalidade, é a mais lídima expressão dos princípios da dignidade da pessoa humana. Ter seu signo, seu pertencimento e suas características psicológicas adaptadas à realidade do seu nome representa condição existencial de paz e harmonia com seu ser. Deve-se atribuir à identidade pessoal o caráter interdisciplinar, de modo a garantir maior satisfação da pessoa humana.

Sobre as tutelas, pode-se agir na defesa preventivamente ou repressivamente. Ao termo "preventivamente", adiciona-se a necessidade de atividade promocional desses direitos, mesmo antes de iminência de ameaça de lesão. Evidencia-se que, a qualquer momento 
pode-selançar mão da tutela judicial desse direito, já que, a Constituição Federal não estabeleceu exigência de jurisdição condicionada ao exaurimento das vias administrativas. As vias judiciais servem aos interessados, mesmo para os casos em que seja possível a tutela pela via extrajudicial, pois se trata de discricionariedade do interessado, como forma de fortalecimento de proteção e acesso à jurisdição.

Todavia, o surgimento de novos instrumentos extrajudiciais corrobora a defesa dos direitos à identidade pessoal. Além do leque, expressamente previsto na Lei de Registros Público, tem-se, ainda, a Emenda Constitucional n $45 / 2004$, que trouxe a garantia da razoável duração do processo e criou o CNJ, órgão administrativo máximo do Poder Judiciário nacional.

Com atuação administrativa e reguladora de normas técnicas para cartórios extrajudiciais, o CNJ possibilitou acesso à justiça, sem necessidade de processo perante um juiz nem intervenção do Ministério Público, quando autorizou ao interessado pleitear diretamente no cartório de registro civil de pessoas naturais alteração, retificação, averbações de dados de assentos registrais pessoais, em franca demonstração do vetor de dignidade da pessoa humana.

Em matéria legislativa, conclui-se que, a gratuidade para atos da vida civil, como certidão de nascimento, óbito e a respectiva emissão da primeira via desses atos, revela-se um instrumento também capaz de estimular, promover o exercício da cidadania de ter um registro oficial do nome, inclusive para obtenção de outros direitos, como inscrição eleitoral e na Receita Federal, assim como acesso a serviços de saúde e educação.

Contudo, necessário observar que, mesmo com tais medidas extrajudiciais promocionais de direitos humanos, verifica-se que existe, ainda, uma cifra, inclusive, de subregistro civil de nascimento, especialmente na região norte, haja vista a falta de conhecimento e desinformação dos direitos básicos para que as pessoas, efetivamente, granjeiem a realização dessa garantia.

Expressa-se relevo do julgamento da $\operatorname{ADI} n^{\circ} 4275$, em que se estabeleceu um caso concreto de domínio público, possibilitando aos transgênero a averbação de prenome e gênero diretamente em cartório, sem a realização de procedimento cirúrgico de redesignação de sexo, sem apresentação de laudos médicos ou psicológicos e sem necessidade de processo judicial e parecer do Ministério Público.

Tal julgamento deu origem ao Provimento $n^{\circ} 73 / 2018$ do $C N J$, que representa um avanço para a concretização do direito ao sexo psicológico, muito embora tenha sido omisso quanta à fonte de custeio desses serviços, o que tem trazido dificuldade na obtenção da gratuidade nos cartórios de registro civil de pessoas naturais, já que a maioria dos potenciais interessados sofre com a exclusão social e familiar. Além disso, não previu possibilidade de pedido por procurador, ao exigir comparecimento pessoal do interessado ao cartório, culminando, em certos casos, na impossibilidade de comparecimento e inviabilidade de acesso a esse serviço.

Salutar o cumprimento de ensinar os direitos humanos, dialogar com as políticas públicas, com o fim de estabelecer meios efetivos de promoção do direito à identidade, garantindo-se acesso à justiça efetivo, ampliando-se medidas extrajudicializadoras e elevando-se a incidência das gratuidades dos serviços de cartórios. 


\section{REFERÊNCIAS}

ALMEIDA, Vitor. A Disciplina jurídica do nome da pessoa humana à luz do direito à identidade pessoal. Revista Jurídica Eletrônica Direito Sociedade e Desenvolvimento. Ano 3, nº 3, p. 1141-1205, 2017. Disponível em: http:// www.ufrrj.br/SEER/index.php?journal=RJEDSD\&page=article\&op=view\&path\%5B\%5D=3471. Acesso em: 28 jun. 2020.

BRASIL. [Constituição (1988)]. Constituição da República Federativa do Brasil. Disponível em: http://www.planalto.gov.br/ccivil_03/constituicao/constituicao.htm. Acesso em: 16 abr. 2020.

BRASIL. Conselho Nacional de Justiça. Provimento $n^{\circ}$ 28, de 5 de fevereiro de 2013. Disponível em: https://atos. cnj.jus.br/atos/detalhar/2525. Acesso em: 27 abr. 2020.

BRASIL. Conselho Nacional de Justiça. Provimento n 63, de 14 de novembro de 2017. Disponível em: https:// atos.cnj.jus.br/atos/detalhar/2525. Acesso em:27 abr. 2020.

BRASIL. Conselho Nacional de Justiça. Provimento $n^{\circ} 73$, de 28 de junho de 2018.Disponível em: https://atos.cnj. jus.br/atos/detalhar/2623. Acesso em: 20 abr. 2020.

BRASIL. Conselho Nacional de Justiça. Provimento $n^{\circ}$ 82, de 3 de julho de 2019. Disponível em: https://atos.cnj. jus.br/atos/detalhar/2973. Acesso em: 20 abr. 2020.

BRASIL. Conselho Nacional de Justiça. Resolução Conjunta 3, de 19 de abril de 2012. Disponível em: http://www. planalto.gov.br/ccivil_03/leis/lcp/Lcp132.htm\#art1. Acesso em: 27 abr. 2020.

BRASIL. Decreto $n^{\circ}$ 592, de 6 de julho de 1992. Pacto internacional de direitos civis e políticos. Disponível em: http://www.planalto.gov.br/ccivil_03/decreto/1990-1994/d0592.htm. Acesso em: 27 abr. 2020.

BRASIL. Emenda Constitucional $n^{\circ} 45$, de 30 de dezembro de 2004. Altera dispositivos dos arts. 50, 36, 52, 92, $93,95,98,99,102,103,104,105,107,109,111,112,114,115,125,126,127,128,129,134$ e 168 da Constituição Federal, e acrescenta os arts. 103-A, 103B, 111-A e 130-A. Disponível em: http://www.planalto.gov.br/ccivil_03/ Constituicao/Emendas/Emc/emc45.htm. Acesso em: 27abr. 2020.

BRASIL. Lei n 6.015, de 31 de dezembro de 1973. Dispõe sobre os registros públicos, e dá outras providências. Disponível em: http://www.planalto.gov.br/ccivil_03/leis/L6015compilada.htm. Acesso em: 18 abr. 2020.

BRASIL. Lei n 8.935, de 18 de novembro de 1997. Regulamenta o art. 236 da Constituição Federal, dispondo sobre serviços notariais e de registro. (Lei dos cartórios). Disponível em:http://www.planalto.gov.br/ccivil_03/ leis/l8935.htm. Acesso em: 28 jun. 2020.

BRASIL. Lei n 9.534, de 10 de dezembro de 1997. Dá nova redação ao art. 30 da Lei nº 6.015, de 31 de dezembro de 1973, que dispõe sobre os registros públicos; acrescenta inciso ao art. $1^{\circ}$ da Lei $n^{\circ} 9.265$, de 12 de fevereiro de 1996, que trata da gratuidade dos atos necessários ao exercício da cidadania; e altera os arts. 30 e 45 da Lei n 8.935, de 18 de novembro de 1994, que dispõe sobre os serviços notariais e de registro. Disponível em: http:// www.planalto.gov.br/ccivil_03/leis/l9534.htm. Acesso em: 27 abr. 2020.

BRASIL. Lei n 10.406, de 10 de janeiro de 2002. Institui o Código Civil. Disponível em: http://www.planalto.gov.br/ ccivil_03/LEIS/2002/L10406.htm. Acesso em: 16 abr. 2020.

BRASIL. Lei n 13.105, de 16 de março de 2015. Código de Processo Civil. Disponível em: http://www.planalto.gov. br/ccivil_03/_ato2015-2018/2015/lei//13105.htm. Acesso em: 18 abr. 2020.

BRASIL. Superior Tribunal Federal. STF reconhece a transgêneros possibilidade de alteração de registro civil sem mudança de sexo. Publicado em $1^{\circ}$ de março de 2018. Disponível em: http://www.stf.jus.br/portal/cms/verNoticiaDetalhe.asp?idConteudo=371085. Acesso em: 28 jun. 2020.

BRASIL. Supremo Tribunal Federal. Ação Direta de Inconstitucionalidade $n^{\circ}$ 4.275.Requerente: Procuradora-Geral da República. Relator: Edson Fachin, $1^{\circ}$ de março de 2018.Disponível em:http://portal.stf.jus.br/processos/downloadPeca.asp?id=15339649246\&ext=.pdf. Acesso em:18 abr. 2020.

BULOS, Uadi Lammêgo. Curso de direito constitucional. 11. ed. São Paulo: Saraiva Educação, 2018. 
CALISSI, Jamile Gonçalves. A Identidade como um direito fundamental articulado a partir dos direitos da personalidade. In: Simpósio Internacional de Análise Crítica do Direito, 7., 2016, Jacarezinho. Anais [...]. BREGA FILHO, Vladimir; MACHADO, Edinilson Donisete; SANCHES, Raquel Cristina Ferraroni (org.). Sistema constitucional de garantia de direito. Jacarezinho: UENP, 2016. Disponível em: http://siacrid.com.br/repositorio/2016/sistema-constitucional-de-garantia-de-direitos.pdf. Acesso em: 20 abr. 2020.

CAPPELLETI, Mauro. Acesso à justiça. Tradução e revisão de Ellen Gracie Northfleet. Porto Alegre: Fabris, 1988.

CÁRCOVA, Carlos Maria. A opacidade do direito. Tradução de Edilson Alkimim Cunha. São Paulo: Ltr, 1998.

COMISSÃO INTERAMERICA DE DIREITOS HUMANOS. Convenção Americana sobre Direitos Humanos de São José da Costa Rica. San José, Costa Rica, 22 nov. 1969. Disponível em: https://www.cidh.oas.org/basicos/portugues/c. convencao_americana.htm. Acesso em: 21 abr. 2020.

CROCE JÚNIOR, Delton. Manual de medicina legal. 8. ed. São Paulo: Saraiva, 2011. p. 63. Disponível em: https:// integrada.minhabiblioteca.com.br/\#/books/9788502149533/. Acesso em: 28 jun. 2020.

EUROPEAN COUT OF HUMAN RIGHTS COUCIL OF EUROPE. Convenção Europeia para a salvaguarda dos direitos do homem e das liberdades fundamentais. Disponível em: https://www.echr.coe.int/Documents/Convention_ POR.pdf. Acesso em: 20 abr. 2020.

FRANÇA, Genival Veloso de. Medicina legal. 10. ed. Rio de Janeiro: Guanabara Koogan, 2015. p. 138. Disponível em: https://www.passeidireto.com/arquivo/76438763/medicina-legal-10-ed-2015-franca-genival-veloso-1. Acesso em: 28 jun. 2020.

GAGLIANO, PabloStolze; PAMPLONA FILHO, Rodolfo. Manual de direito civil. 2. ed. São Paulo: SaraivaJur, 2018. Disponível em: https://integrada.minhabiblioteca.com.br/\#/books/9788553172764/. Acesso em: 21 abr. 2020.

GOMES, Orlando. Introdução ao direito civil. 22. ed. Rio de Janeiro: Forense, 2019.

GUIMARÃES, Raphael Pinheiro Cavalcanti. O procedimento de registro tardio de nascimento à luz da Provimento $\mathrm{n}^{\circ} 28$ do Conselho Nacional de Justiça. Âmbito Jurídico, Rio Grande, XVIII, n. 142, nov. 2015. Disponível em: http:// www.ambitojuridico.com.br/site/index.php?n_link=revista_artigos_leitura\&artigo_id=16583\&revista_caderno=7. Acesso em: 20 abr. 2020.

HOGEMANN, Edna Raquel; MOURA, Solange Ferreira de. O direito fundamental à identidade pessoal e o estigma do abandono. Revista Interdisciplinar de Direito, v. 9, n. 1, p. 55-68, maio 2018. ISSN 2447-4290. Disponível em: http://revistas.faa.edu.br/index.php/FDV/article/view/504. Acesso em: $1^{\circ}$ jul. 2020.

INSTITUTO BRASILEIRO GEOGRAFIA E ESTATÍSTICA. Estatística do registro civil 2017. Estat. Reg. Civ., Rio de Janeiro, v. 44, p. 1-8, 2019. Disponível em: https://biblioteca.ibge.gov.br/visualizacao/periodicos/135/rc_2017_ v44_informativo.pdf. Acesso em: 20 abr. 2020.

KANT, Immanuel. Fundamentação da metafísica dos costumes. Trad. de Guido Antônio de Almeida. São Paulo: Discurso Editorial: Barcarolla, 2009. Disponível em: http://www.dhnet.org.br/direitos/anthist/marcos/hdh_kant_ metafisica_costumes.pdf. Acesso em: 25 maio 2020.

KONDER, Carlos Nelson de Paula. O Alcance do direito à identidade pessoal no direito civil brasileiro. Pensar, Fortaleza, v. 23, n. 1, p. 1-11, jan./mar. 2018. Disponível em: https://periodicos.unifor.br/rpen/article/view/7497. Acesso em: 20 abr. 2020

LOUREIRO, Luiz Guilherme. Registros públicos: teoria e prática. 9. ed. rev., atual. eampl. Salvador: Juspodivm, 2018.

MENEZES, Joyceane Bezerra de; LNS, Ana Paola de Castro e. Identidade de gênero e transexualidade no direito brasileiro. Revista Brasileira de Direito Civil. Belo Horizonte, v. 17, p. 17-41, jul./set. 2018. Disponível em: par. Acesso em: $1^{\circ}$ jul. 2020.

NAÇÕES UNIDAS BRASIL. Declaração universal dos direitos humanos. 1948. Disponível em: https://nacoesunidas.org/wp-content/uploads/2018/10/DUDH.pdf. Acesso em: 20 abr. 2020.

PIOVESAN, Flávia. Direitos humanos e justiça internacional: um estudo comparativo dos sistemas regionais europeu, interamericano e africano. Prefácio de Celso Lafer. 9. ed. rev. e atual. São Paulo: Saraiva Educação, 2019. 
RAMOS, André de. Carvalho curso de direitos humanos. 7. ed. São Paulo: Saraiva Educação, 2020.

REALE, Miguel. Filosofia do direito. São Paulo: Saraiva, 2002.

RODRIGUES, Marcelo Guimarães. Tratado de registros públicos e direito notarial. 2. ed. São Paulo: Atlas, 2016.

UNESCO. Declaração Universal sobre o Genoma Humano e os Direitos Humanos. In: 29a Sessão da Conferência Geral da Unesco. Novembro 11, 1997. Disponível em: http://www.ghente.org/doc_juridicos/dechumana.htm1. Acesso em: 28 jun. 2020.

Recebido/Received: 30.05.2020.

Aprovado/Approved: 09.07.2020 